- cardioplegia administered simultaneously into the ascending aorta and isolated MPA/proximal branch PA; and

- reimplantation of ALCAPA with generous buttons to avoid distortion.

Alternative options would be a hybrid approach with PA banding distal to ALCAPA and reimplantation at time of comprehensive stage II, or neonatal transplantation.

\section{CONCLUSIONS}

The preoperative diagnosis of this rare entity is key because it allows for adequate surgical planning.

\section{References}

1. Dodge-Khatami A, Mavroudis C, Backer C. Anomalous origin of left coronary from pulmonary artery: collective review of surgical therapy. Ann Thorac Surg. 2002;74:946-55.

2. Saroli T, Gelehrter S, Gomez-Fifer CA, van der Velde ME, Bove EL, Ensing GJ. Anomalies of left coronary artery origin affecting surgical repair of hypoplastic left heart syndrome and Shone complex. Echocardiography. 2008;25:727-31. Epub 2008 Apr 27

3. Nosal M, Omeje IC, Poruban R. Hypoplastic left heartsyndrome with anomalous origin of left coronary artery from the right pulmonary artery: successful surgical treatment in a neonate. Eur J Cardiothorac Surg. 2005;28:497-8.

4. Bartram U, Grunenfelder J, Van Praagh R. Causes of death after the modified Norwood Procedure: a study of 122 postmortem cases. Ann Thorac Surg. 1997;64: 1795-802.

5. Daebritz SH, Nollert GD, Zurakowski D, Khalil PN, Lang P, del Nido PJ, et al. Results of Norwood stage I operation: comparison of hypoplastic left heart syndrome with other malformations. J Thorac Cardiovasc Surg. 2000; 119:358-67.

\title{
Percutaneous mitral valve repair as a bail-out strategy for patients with severe mitral regurgitation after cardiac surgery
}

\author{
Olaf Franzen, MD, ${ }^{\mathrm{a}}$ Moritz Seiffert, MD, ${ }^{\mathrm{b}}$ Stephan Baldus, MD, ${ }^{\mathrm{a}}$ Lenard Conradi, MD, ${ }^{\mathrm{b}}$ \\ Johannes Schirmer, MD, ${ }^{\mathrm{b}}$ Mathias Kubik, MD, ${ }^{\mathrm{b}}$ Thomas Meinertz, MD, ${ }^{\mathrm{a}}$ \\ Hermann Reichenspurner, MD, PhD, ${ }^{\mathrm{b}}$ and Hendrik Treede, MD, ${ }^{\mathrm{b}}$ Hamburg, Germany
}

With excellent long-term results, surgical valve repair is the standard treatment in patients with mitral valve (MV) disease, replacement being an option if reconstruction is not feasible. ${ }^{1,2}$ In patients with prohibitive operative risk, the MitraClip system (Abbott Laboratories, Abbott Park, Ill) has accomplished promising preliminary results reducing mitral regurgitation (MR). ${ }^{3,4}$ We performed this procedure as a bail-out approach in high-risk patients with severe MR not responding to intense medical therapy in the early postoperative period after cardiac surgery.

\section{CLINICAL SUMMARY}

From March to October 2009, 3 patients underwent coronary artery bypass grafting, tricuspid valve replacement, or

\footnotetext{
From the Departments of General and Interventional Cardiology, ${ }^{\mathrm{a}}$ and Cardiovascular Surgery, ${ }^{\text {b }}$ University Heart Center Hamburg, Germany.

Disclosures: Dr Franzen received funding for proctoring from E-Valve Inc, Menlo Park, California, and Abbott Laboratories, Abbott Park, Illinois.

Drs Franzen and Seiffert contributed equally to this work.

Received for publication May 18, 2010; accepted for publication Oct 23, 2010; available ahead of print Jan 19, 2011.

Address for reprints: Moritz Seiffert, MD, Department of Cardiovascular Surgery, University Heart Center Hamburg, Martinistrasse 52, 20246 Hamburg, Germany

(E-mail: m.seiffert@uke.de).

J Thorac Cardiovasc Surg 2011;142:227-30

$0022-5223 / \$ 36.00$

Copyright (C) 2011 by The American Association for Thoracic Surgery doi: $10.1016 /$ j.jtcvs. 2010.10 .037
}

aortic valve replacement combined with tricuspid valve repair at the University Heart Center Hamburg (Table 1). Preoperatively, mild to moderate MR was noted. Postoperatively, severe functional MR impeded hemodynamic stabilization necessitating prolonged inotropic support. To avoid early redo surgery associated with disproportional operative risk, an interventional approach was chosen after interdisciplinary discussion.

Percutaneous MV repair was performed with the MitraClip device, a polyester-covered metal clip, as previously described. ${ }^{5}$ Briefly, after introduction through the femoral vein and transseptal puncture, the steerable device was advanced across the MV. The clip was then positioned, and the leaflets were captured at the origin of the regurgitant jet creating a double-orifice simulating Alfieri's technique. Clip implantation was performed under fluoroscopic and transesophageal echocardiographic guidance (Figure 1). Follow-up echocardiographic evaluation was performed at discharge and 3 months after the procedure.

\section{RESULTS}

All 3 female patients (age, 71-78 years) were considered high-risk surgical candidates as predicted by standard risk-stratification tools (Table 1). Percutaneous MV repair was performed 5 to 7 days after primary surgery. Two clips were used in 2 of the patients, creating a triple-orifice area. MR was reduced from grade III-IV to I-II allowing for hemodynamic recompensation. There were no signs of mitral stenosis after clip implantation. 
TABLE 1. Clinical and procedural characteristics

\begin{tabular}{|c|c|c|c|}
\hline Patients & 1 & 2 & 3 \\
\hline \multicolumn{4}{|l|}{ Baseline clinical characteristics } \\
\hline Age (y) & 78 & 76 & 71 \\
\hline Gender & Female & Female & Female \\
\hline BMI $\left(\mathrm{kg} / \mathrm{m}^{2}\right)$ & 18 & 26 & 24 \\
\hline Morbidities and medical history & $\begin{array}{c}\text { Severe CAD } \\
\text { Persistent atrial fibrillation } \\
\text { Arterial hypertension } \\
\text { S/p surgery and radiation therapy } \\
\text { for breast cancer }\end{array}$ & $\begin{array}{c}\text { Severe AS (III) } \\
\text { Severe TR (IV) } \\
\text { S/p pacemaker-implantation for } \\
\text { bradyarrhythmia } \\
\text { Arterial hypertension } \\
\text { Cerebrovascular stroke }\end{array}$ & $\begin{array}{c}\text { Severe TR (IV) } \\
\text { Valvular cardiomyopathy } \\
\text { Intermittent atrial fibrillation } \\
\text { Arterial hypertension } \\
\text { Renal dysfunction }\end{array}$ \\
\hline Primary surgery & $\begin{array}{l}\text { Quadruple CABG } \\
\text { Biatrial ablation }\end{array}$ & $\begin{array}{l}\text { AV replacement (Mitroflow [Sorin } \\
\text { Group, Milano, Italy] } 21 \mathrm{~mm} \text { ) } \\
\text { TV repair (Carpentier-Edwards } \\
\text { [Edwards Lifesciences, Irvine, Calif] } \\
\text { Classic annuloplasty ring } 28 \mathrm{~mm} \text { ) }\end{array}$ & $\begin{array}{l}\text { TV replacement (Hancock } \\
\text { [Medtronic Inc, Minneapolis, } \\
\text { Minn] } 31 \mathrm{~mm}) \\
\text { Biatrial ablation }\end{array}$ \\
\hline Preoperative/postoperative MR & $\mathrm{I}-\mathrm{II} / \mathrm{III}$ & II/III-IV & $\mathrm{I} / \mathrm{IV}$ \\
\hline MV pathology & $\begin{array}{l}\text { MV annulus dilatation with } \\
\text { coaptation gap, increased } \\
\text { postoperatively }\end{array}$ & $\begin{array}{c}\text { Bileaflet prolapse } \\
\text { Aggravated MR postoperatively }\end{array}$ & $\begin{array}{l}\text { New-onset functional restriction } \\
\text { of PML postoperatively }\end{array}$ \\
\hline Ventricular function & Poor LV function & Poor LV function & $\begin{array}{c}\text { Moderate LV function } \\
\text { RV failure }\end{array}$ \\
\hline NYHA & IV & IV & IV \\
\hline Logistic euroSCORE & $60.3 \%$ & $50.8 \%$ & $70.8 \%$ \\
\hline STS score for Mortality & $14.0 \%$ & $9.1 \%$ & $38.4 \%$ \\
\hline \multicolumn{4}{|c|}{ Intra-/postprocedural characteristics } \\
\hline Days after primary surgery & 7 & 5 & 7 \\
\hline No. of implanted clips & 2 & 2 & 4 \\
\hline Procedure time & $221 \mathrm{~min}$ & $201 \min$ & $300 \mathrm{~min}$ \\
\hline Fluoroscopy time & $40 \mathrm{~min}$ & $31 \mathrm{~min}$ & $61 \mathrm{~min}$ \\
\hline MR & I-II & I-II & II-III \\
\hline MV EOA & $2.5 \mathrm{~cm}^{2}$ & $2.0 \mathrm{~cm}^{2}$ & $2.2 \mathrm{~cm}^{2}$ \\
\hline MV gradient & $6 / 4 \mathrm{~mm} \mathrm{Hg}$ & $10 / 3 \mathrm{~mm} \mathrm{Hg}$ & $8 / 4 \mathrm{~mm} \mathrm{Hg}$ \\
\hline \multicolumn{4}{|l|}{ 3-mo follow-up } \\
\hline NYHA & II & II-III & IV \\
\hline MR & $\mathrm{I}$ & II & III \\
\hline Ventricular function & Normal LV function & Normal LV function & $\begin{array}{l}\text { Moderate LV function } \\
\text { RV dysfunction }\end{array}$ \\
\hline
\end{tabular}

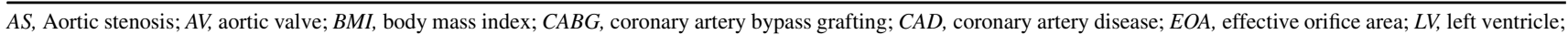
$M R$, mitral regurgitation; $M V$, mitral valve; $N Y H A$, New York Heart Association functional class; $P M L$, posterior mitral leaflet; RV, right ventricle; STS, Society of Thoracic Surgeons; $T R$, tricuspid regurgitation; $T V$, tricuspid valve.

These patients were discharged to a rehabilitation facility shortly thereafter and presented with enhanced ventricular function and MR grade II at 3 months follow-up. New York Heart Association status had improved from class IV to II/III.

In 1 patient, restricted leaflet motion caused an almost free MR after tricuspid valve replacement. Valve morphology and a large coaptation gap of $13 \mathrm{~mm}$ between anterior and posterior leaflets prevented regular clip implantation at the origin of the MR jet for sufficient reduction of regurgitation. Instead, 4 clips were implanted in a zipper-like approach as a rare modification of the technique. Approximation of the leaflets was achieved by clip implantation beginning at the lateral aspects of the coaptation gap and proceeding to the central part, thus reducing MR to grade II-III (Figure 1) and allowing for hemodynamic stabilization and weaning of inotropic support. Three months after initial surgery, this patient was still hospitalized. Respiratory failure with prolonged ventilation, renal failure, and critical illness neuropathy in addition to the remaining MR complicated this patient's postoperative course. Follow-up echocardiography displayed slightly improved left ventricular function and persistent right ventricular dysfunction.

\section{CONCLUSIONS}

Our patients were not candidates for early redo surgery to repair the MV because of significant comorbidities and hemodynamic instability; thus, an interventional approach 


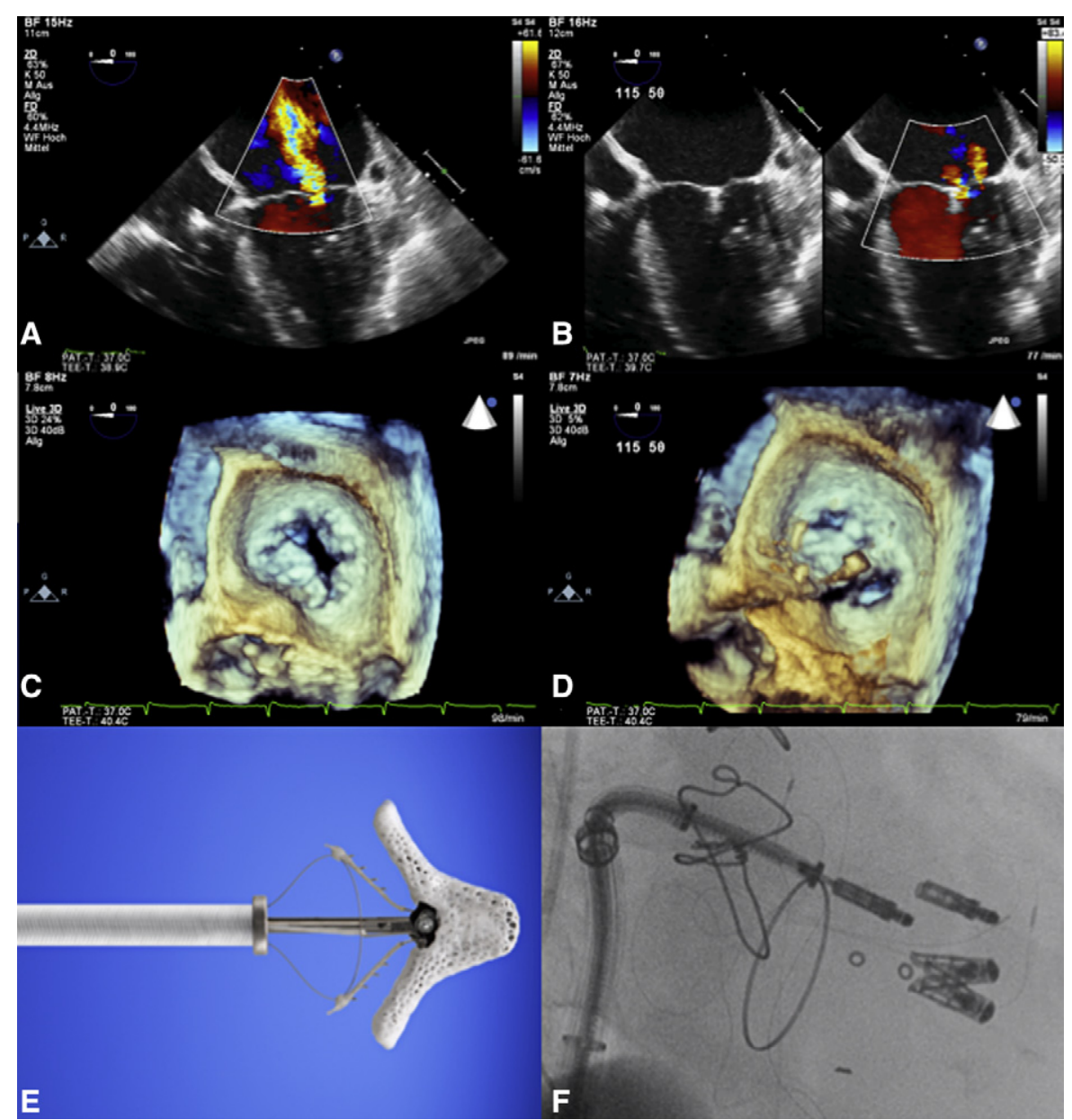

FIGURE 1. Transesophageal Doppler echocardiography displaying the regurgitation jet before (A) and after (B) MitraClip (Abbott Laboratories, Abbott Park, IL) implantation. Intraprocedural 3-dimensional transesophageal echocardiography displaying the MV before (C) and after (D) implantation of 2 clips creating a triple-orifice area, with the steerable catheter still in place (D). MitraClip attached to the delivery catheter (E) (reprinted with permission from Abbott Laboratories) and fluoroscopic control while positioning a fourth clip in patient number 3 with 3 clips already in place (F).

with the MitraClip device proved to be a valuable bail-out strategy. Mild to moderate MR had been observed preoperatively in all patients without indication for MV surgery following recent guidelines. ${ }^{1}$ Different causes were presumably responsible for the increase in MR postoperatively, one being progressing annular dilatation. The impact of MR was underestimated intraoperatively and the MV was left alone to reduce exposition to extracorporeal circulationa shortsighted judgment in retrospect (patient 1). An increased volume challenge to the left ventricle with dilatation after tricuspid valve surgery may account for an aggravated MR, bileaflet prolapse (patient 2) and an increased coaptation gap caused by functional restriction of the posterior mitral leaflet (patient 3) being the underlying pathologies.

The MitraClip device was used to reduce regurgitation and allow for hemodynamic stabilization, the potential goal being definite valve repair or postponement of surgical MV therapy to a later elective stage with a reduced operative risk. The implantation of multiple clips and prolonged recompensation in 1 patient underscore the complexity. Furthermore, the percutaneous approach falls short of a ring annuloplasty, and the long-term implications on the durability remain to be elucidated. Nevertheless, because of the promising results in this high-risk patient cohort, application in hemodynamically stable postoperative patients in whom severe MR develops seems conceivable, sparing these patients the burden of early redo surgery with repeat exposition to extracorporeal circulation. The utility of this technique needs to be validated in a larger population and over a longer follow-up period.

\section{References}

1. Bonow RO, Carabello BA, Chatterjee K, de Leon AC Jr, Faxon DP, Freed MD, et al. 2008 Focused update incorporated into the ACC/AHA 2006 guidelines for the management of patients with valvular heart disease: a report of the American College of Cardiology/American Heart Association Task Force on Practice Guidelines (Writing Committee to Revise the 1998 Guidelines for the Management of Patients With Valvular Heart Disease): endorsed by the Society of Cardiovascular Anesthesiologists, Society for Cardiovascular Angiography 
and Interventions, and Society of Thoracic Surgeons. Circulation. 2008;118: e523-661

2. Carabello BA. The current therapy for mitral regurgitation. J Am Coll Cardiol. 2008;52:319-26.

3. Feldman T, Kar S, Rinaldi M, Fail P, Hermiller J, Smalling R, et al. Percutaneous mitral repair with the MitraClip system: safety and midterm durability in the initial EVEREST (Endovascular Valve Edge-to-Edge REpair Study) cohort. J Am Coll Cardiol. 2009;54:686-94.
4. Franzen O, Baldus S, Rudolph V, Meyer S, Knap M, Koschyk D, et al. Acute outcomes of MitraClip therapy for mitral regurgitation in high-surgical-risk patients: emphasis on adverse valve morphology and severe left ventricular dysfunction. Eur Heart J. 2010;31:1373-81.

5. Feldman T, Wasserman HS, Herrmann HC, Gray W, Block PC, Whitlow P, et al. Percutaneous mitral valve repair using the edge-to-edge technique: six-month results of the EVEREST Phase I Clinical Trial. J Am Coll Cardiol. 2005;46: 2134-40.

\title{
Perventricular device closure of post-myocardial infarction ventricular septal defect on the beating heart
}

\author{
Barry A. Love, MD, ${ }^{a}$ Brian Whang, MD, ${ }^{\mathrm{b}}$ and Farzan Filsoufi, MD, ${ }^{\mathrm{b}}$ New York, NY
}

We report 2 cases of post-myocardial infarction ventricular septal defect (PMI-VSD) closed successfully with Amplatzer septal occluders (AGA Medical Corp, Plymouth, Minn) using a direct perventricular approach via median sternotomy. The procedures were performed on the beating heart without cardiopulmonary bypass.

\section{CLINICAL SUMMARY}

We describe 2 sexagenarian men hospitalized with acute myocardial infarction and cardiogenic shock. In each, cardiac catheterization revealed proximal occlusion of the left anterior descending artery, and ventriculogram demonstrated a large PMI-VSD. Step-up in pulmonary artery saturation indicated pulmonary-to-systemic flow ratio of $3: 1$ and greater than $4: 1$ in each patient. Both received an intra-aortic balloon pump and were referred for emergency PMI-VSD closure.

Intraoperative transesophageal echocardiography in both patients confirmed a large mid-muscular PMI-VSD (patient $1,25 \mathrm{~mm}$; patient 2,28 $\mathrm{mm}$ ) extending to the apex with leftto-right shunt (Figure 1, $A, B$ ). A median sternotomy was performed. Digital compression of the right ventricular (RV) free wall identified the site on the RV directly opposite the central portion of the PMI-VSD (Figure 1,C). In both patients, this was approximately $4 \mathrm{~cm}$ basal to the cardiac apex. A purse-string was placed, and an $18 \mathrm{~g}$ needle was

From the Division of Pediatric Cardiology a and Department of Cardiothoracic Surgery, ${ }^{\mathrm{b}}$ Mount Sinai School of Medicine, New York, NY.

Disclosures: Authors have nothing to disclose with regard to commercial support.

Received for publication March 20, 2010; accepted for publication Oct 22, 2010; available ahead of print Jan 19, 2011.

Address for reprints: Barry A. Love, MD, Assistant Professor of Pediatrics, Mount Sinai Medical Center, Box 1201, 1 Gustave L Levy Place, New York, NY 10029 (E-mail: barry.love@mssm.edu).

J Thorac Cardiovasc Surg 2011;142:230-2 0022-5223/ $\$ 36.00$

Copyright $₫ 2011$ Published by Elsevier Inc. on behalf of The American Association for Thoracic Surgery

doi:10.1016/j.jtcvs.2010.10.039 inserted through the purse-string, into the central portion of the VSD, and into the LV cavity. A 0.038-inch-30-cm J-wire was inserted into the LV. A 12F 13-cm Cook sheath was advanced over the guidewire. In each patient, a 34-mm Amplatzer septal occluder was then deployed. The distal disc was delivered in the LV cavity and pulled flush with the LV septum. With traction on the delivery system and countertraction on the RV free wall, the proximal disc was deployed on the exterior surface of the RV (Figure 2, A$C)$. A $34-\mathrm{mm}$ device was chosen so the left disc $(50 \mathrm{~mm})$ would cover the defect and the adjacent infarcted muscle, and extend to what appeared to be viable myocardium.

In the first patient, transesophageal echocardiography showed closure of the VSD with minimal residual flow (Figure 2, D). On postoperative day (POD) 1, he was extubated and the intra-aortic balloon pump was removed. Echocardiogram on POD 5 showed a tiny residual VSD, an LV ejection fraction of $35 \%$, and normal RV. The patient was discharged on POD 5. He remained well for 3 weeks but returned in acute low-output cardiac failure. Echocardiogram showed minimal residual shunting but severely depressed biventricular function. Despite inotropic support, progressive acidosis developed and the patient died within 24 hours.

The second patient underwent off-pump left anterior descending artery revascularization in the same setting, and he was extubated on POD 1. Follow-up catheterization on POD 10 showed a small residual VSD that was successfully closed with a transcatheter Amplatzer muscular VSD occluder. The patient was discharged, and repeat catheterization 5 months later showed minimal residual left-to-right flow and a shunt fraction of less than 1.2:1. At 13 months postoperatively, the patient is in New York Heart Association class I-II.

\section{DISCUSSION}

VSD complicates $0.2 \%$ of cases of acute myocardial infarction. $^{1}$ Most of these patients present with rapid 